\title{
Mina53 nuclear localization is an important indicator of prognosis in patients with colorectal cancer after adjuvant chemotherapy
}

\author{
SHINYA FUJINO ${ }^{1}$, TETSUSHI KINUGASA ${ }^{1}$, TOMOYA SUDO ${ }^{1,2}$, TOMOAKI MIZOBE ${ }^{1}$, TAKEFUMI YOSHIDA ${ }^{1}$, \\ NAOHIRO YOSHIDA ${ }^{1}$, TAKAFUMI OHCHI ${ }^{1}$, KENSUKE TAJIRI $^{1}$, KOTARO YUGE ${ }^{1}$, \\ SACHIKO NAGASU ${ }^{1}$, MITSUHIRO KATAGIRI ${ }^{1}$ and YOSHITO AKAGI $^{1}$ \\ ${ }^{1}$ Department of Surgery, ${ }^{2}$ Research Center for Innovative Cancer Therapy, \\ Kurume University School of Medicine, Fukuoka 830-0011, Japan
}

Received November 17, 2017; Accepted April 4, 2018

DOI: 10.3892/or.2018.6407

\begin{abstract}
The aim of this study was to investigate the status of the c-Myc-related molecule Mina53 and the clinical impact of Mina53 nuclear localization in patients with stage II and III colorectal cancer $(\mathrm{CRC})$. Patients $(n=250)$ who underwent complete resection of CRC at our department were enrolled in this study, and tissue microarray samples were constructed from resected specimens. Mina53 expression in the nuclei of tumor cells was analyzed using immunohistochemistry (IHC). Patients were classified into Mina53 nuclear localizationpositive and -negative groups, and statistical correlations with clinicopathological factors were investigated. Relapse-free survival (RFS) was compared using the Kaplan-Meier method and the Cox proportional hazard model. Tumor recurrence was significantly higher in the Mina53-positive group than in the Mina53-negative group. Moreover, in RFS analysis, patients in the Mina53-positive group exhibited significantly poorer prognosis than patients in the Mina53-negative group. In the univariate analysis, histological type, adjuvant chemotherapy status, carcinoembryonic antigen (CEA) status, and Mina53 status were prognostic factors for RFS. Furthermore, in the subgroup analysis, patients in the Mina53-positive group with stage III disease treated with adjuvant chemotherapy exhibited significantly poorer prognosis in RFS than patients in the Mina53-negative group. In the univariate and multivariate analyses, histological type and Mina53 status were
\end{abstract}

Correspondence to: Dr Tetsushi Kinugasa, Department of Surgery, Kurume University School of Medicine, 67 Asahi-machi, Kurume, Fukuoka 830-0011, Japan

E-mail: kinugasa_tetsushi@med.kurume-u.ac.jp

Abbreviations: Mina53, Myc-induced nuclear antigen with a molecular weight of $53 \mathrm{kDa}$

Key words: Mina53, c-Myc, prognostic indicator, colorectal cancer stage III significantly associated with RFS. Thus, our findings revealed that Mina53 was an important indicator of prognosis in patients with stage III CRC treated with adjuvant chemotherapy.

\section{Introduction}

Colorectal cancer (CRC) is the third leading cause of cancer-related deaths, and more than 130,000 people are diagnosed with CRC annually in the United States of America (1). In Japan, CRC is the second leading cause of cancer-related deaths, and out of 360,000 cancer-related deaths in Japan, more than 50,000 were caused by CRC $(2,3)$. The treatment of advanced $\mathrm{CRC}$ has evolved from single modality treatment to multimodal treatment. However, some patients still experience tumor recurrence and metastasis, even after curative resection of the tumor and administration of adjuvant chemotherapy. Therefore, it is necessary to identify novel biomarkers for prediction of the risk of recurrence or metastasis in high-risk patients.

Several studies have identified clinicopathological and biological markers that predict the prognosis of patients with CRC after administration of adjuvant chemotherapy. For example, Shirota et al reported that thymidylate synthase mRNA levels predicted survival in patients with CRC receiving a combination of oxaliplatin and fluorouracil (5FU) adjuvant chemotherapy (4). Additionally, Crozier et al demonstrated that the prognosis of patients with CRC after $5 \mathrm{FU}$ adjuvant chemotherapy was poor in cases exhibiting high systemic inflammatory responses (5). Ogata et al revealed that the expression of vascular endothelial growth factor (VEGF) was associated with the prognosis of patients treated with adjuvant UFT and 5'-DFUR therapy (6). Furthermore, Ogawa et al demonstrated that thymidine phosphorylase mRNA expression is an effective marker predicting prognosis in patients who received S-1 adjuvant chemotherapy (7). These biomarkers may become specific indicators for the corresponding drugs. However, if the therapeutic regimen is combined with multiple drugs, these biomarkers generally cannot predict patient outcomes. Thus, it is necessary to develop biomarkers that can clearly and broadly predict the 
outcome of various adjuvant chemotherapies. Myc-induced nuclear antigen with a molecular weight of $53 \mathrm{kDa}$ (Mina53), also known as ribosomal oxygenase 2 (RIOX2), is a novel Myc target gene located on chromosome 3q11.1. This gene was initially identified by Tsuneoka et al (8). The Mina53 protein is not expressed in cells of the normal colonic mucous membrane, but is induced directly by c-Myc, an important oncogene (9). Moreover, the Mina53 protein is localized in the nucleus and nucleolus. Following induction by c-Myc, Mina53 in the nucleus and nucleolus contributes to cell proliferation. Therefore, the localized expression of Mina53 in the nucleus can be an important indicator of cancer cell proliferation. Furthermore, Tsuneoka et al reported that specific inhibition of Mina53 expression by RNA interference markedly suppresses cell proliferation (8). However, the correlation between the intracellular localization of Mina53 and clinicopathological factors in CRC is still unknown.

Accordingly, in this study, we aimed to investigate the cellular localization patterns of Mina53 in CRC tissues and to assess the clinical significance of the nuclear expression of Mina53 as a biomarker in patients with CRC after adjuvant therapy.

\section{Materials and methods}

Patients. A total of 636 patients who were diagnosed with CRC and underwent curative resection of the tumor in our department from 2005 to 2008 were enrolled in this study. Patients who underwent additional colorectal resection after endoscopic mucosal resection (EMR) of the primary tumor, patients lacking clinical information, and patients who had received neoadjuvant chemotherapy were excluded from the study. Clinical records and pathological reports were closely reviewed retrospectively.

Among the included cases, 250 patients were diagnosed with pathological stage II or III in accordance with the seventh edition of the UICC TNM classification of malignant tumors. All patients received curative resection of the tumor, including D3 regional lymphadenectomy. Thirty-eight of the 137 patients with stage II disease and 64 of the 113 patients with stage III disease received adjuvant therapy. The backgrounds and selection of patients are summarized in Fig. 1 and Table I.

Institutional review board statement. All of the protocols used in this study were in compliance with the guidelines of the Ethics Committee of Kurume University School of Medicine. The protocol of the study was approved by the hospital Ethics Review Board (no. 203), and informed consent was obtained from all of the enrolled patients pre-operatively.

Immunohistochemical analysis of tissue microarray (TMA). Tissue samples were obtained from the selected patients after surgery, and formalin-fixed, paraffin-embedded blocks were created. One cylindrical core biopsy with a diameter of $3.0 \mathrm{~mm}$ was punched out from the center of every tumor tissue sample using a tissue microarray instrument. These samples were assembled and embedded in a recipient paraffin block to make a TMA sample.

A $4-\mu$ m section was cut from this TMA block and used for immunohistochemical staining. Paraffin sections were deparaffinized in xylene and rehydrated in graded ethanol. Microwave-mediated antigen retrieval was performed in $0.01 \mathrm{M}$ citrate buffer, $\mathrm{pH}$ 6.0. Endogenous peroxidase activity was blocked with $0.3 \%$ hydrogen peroxide in methanol for $15 \mathrm{~min}$. Sections were incubated at room temperature with anti-Mina53 antibody (dilution 1:100; cat. no. ab126282; Abcam, Cambridge, MA). Immunohistochemical staining was performed using the Dako Chem Mate EnVision system (Dako, Glostrup, Denmark) and a Peroxidase/DAB Kit (Dako). Sections were counterstained with hematoxylin, the slides were dehydrated, coverslipped and observed in a x100 magnifying field with a microscope (Olympus BX51; Olympus Optical, Co., Ltd., Tokyo, Japan). Images were thoroughly evaluated by two independent pathologists.

Statistical analysis. Patients were divided into Mina53 nuclear expression-positive and -negative groups. The Chi-squared test was used to evaluate the significance of correlations between groups. Survival curves were computed by the Kaplan-Meier method and statistical significance was assessed by the log-rank test. Univariate and multivariate analyses were performed using the Cox proportional-hazard model, and are summarized using false-discovery rate comparisons. Findings with P-values $<0.05$ were considered to indicate a statistically significant difference. All statistical analyses were performed using the computational statistical software JMP version 11.0 (SAS Institute, Cary, NC, USA).

\section{Results}

Patient backgrounds and evaluation of Mina53. A flowchart of the selection process and a summary of the enrolled patients are presented in Fig. 1 and Table IA. There were significant differences in tumor depth and lymph node metastasis between patients with stage II and stage III disease. Furthermore, lymphatic invasion, vascular invasion, tumor budding and perineural invasion (PNI) were more common in patients with stage III disease than in patients with stage II disease. However, there were no significant differences in tumor size, tumor location, and tumor marker expression between patients with stage II and stage III disease. Adjuvant chemotherapy was performed in $27 \%$ of patients with stage II disease and $56.64 \%$ of patients with stage III disease; this difference was statistically significant. The percentages of recurrence were $16.8 \%$ in patients with stage II disease and $24.8 \%$ in patients with stage III disease. The patterns of recurrence are summarized in Table IB. There were no significant differences in recurrence form between patients with stage II and III disease.

To evaluate the clinical impact of Mina53 nuclear staining in patients with stage II and III CRC, immunohistochemical analysis using a TMA was performed, and clinicopathological factors were investigated. Representative cases of immunostaining of Mina53 are shown in Fig. 2. Primary tumor cells displayed several Mina53 staining patterns. As shown in Fig. 2A, Mina53 was clearly stained in the nucleus of tumor cells. Fig. 2B shows Mina53 staining in both the cytoplasm and nucleus of tumor cells. In Fig. 2C, Mina53 was present in the cytoplasm but not in the nucleus of tumor cells. Finally, Fig. 2D shows negative results for Mina53 staining in tumor cells. We defined Mina53 positivity as shown in Fig. 2A and B. 
Table I. Clinicopathological backgrounds and summary of recurrence of patients with stage II and stage III disease enrolled in this study.

A, Clinicopathological backgrounds of patients enrolled in this study

\begin{tabular}{|c|c|c|c|}
\hline Clinicopathological variables & Stage II $n=137(\%)$ & Stage III n=113 (\%) & P-value \\
\hline \multicolumn{4}{|l|}{ Sex } \\
\hline Male & $94(68.6)$ & $69(61.1)$ & \multirow[t]{2}{*}{0.21} \\
\hline Female & $43(31.4)$ & $44(38.9)$ & \\
\hline Age, average \pm SD & $67.83 \pm 11.27$ & $67.68 \pm 11.97$ & 0.91 \\
\hline \multicolumn{4}{|l|}{$\mathrm{T}$ grade } \\
\hline $\mathrm{T} 1$ & $0(0)$ & $3(2.65)$ & \multirow[t]{4}{*}{$<0.0001^{\mathrm{a}}$} \\
\hline $\mathrm{T} 2$ & $0(0)$ & $13(11.5)$ & \\
\hline $\mathrm{T} 3$ & $60(43.8)$ & $89(78.76)$ & \\
\hline $\mathrm{T} 4$ & $77(56.2)$ & $8(7.08)$ & \\
\hline \multicolumn{4}{|l|}{$\mathrm{N}$ grade } \\
\hline NO & $137(100)$ & $0(0)$ & \multirow[t]{4}{*}{$<0.0001^{\mathrm{a}}$} \\
\hline N1 & $0(0)$ & $89(78.76)$ & \\
\hline $\mathrm{N} 2$ & $0(0)$ & $18(15.93)$ & \\
\hline $\mathrm{N} 3$ & $0(0)$ & $6(5.31)$ & \\
\hline Tumor size, $\mathrm{mm}$, average $\pm \mathrm{SD}$ & $51.21 \pm 23.0$ & $48.93 \pm 19.87$ & 0.41 \\
\hline \multicolumn{4}{|l|}{ Location } \\
\hline Colon & $85(62.04)$ & $75(66.37)$ & \multirow[t]{2}{*}{0.47} \\
\hline Rectum & $52(37.96)$ & $38(33.63)$ & \\
\hline \multicolumn{4}{|l|}{ Histological type } \\
\hline Well-mod & $128(93.43)$ & $100(88.5)$ & \multirow[t]{2}{*}{0.17} \\
\hline Others & $9(6.57)$ & $13(11.5)$ & \\
\hline \multicolumn{4}{|l|}{ Lymphatic invasion } \\
\hline Negative & $67(48.91)$ & $28(24.78)$ & \multirow[t]{2}{*}{$<0.0001^{\mathrm{a}}$} \\
\hline Positive & $70(51.09)$ & $85(75.22)$ & \\
\hline \multicolumn{4}{|l|}{ Vascular invasion } \\
\hline Negative & $31(22.63)$ & $17(15.04)$ & \multirow[t]{2}{*}{0.12} \\
\hline Positive & $106(77.37)$ & $96(84.96)$ & \\
\hline \multicolumn{4}{|l|}{ Budding } \\
\hline Negative & $52(38.24)$ & $29(25.66)$ & \multirow[t]{2}{*}{$0.034^{\mathrm{a}}$} \\
\hline Positive & $84(61.76)$ & $84(74.34)$ & \\
\hline \multicolumn{4}{|l|}{ Perineural invasion } \\
\hline Negative & $116(84.67)$ & $80(70.80)$ & \multirow[t]{2}{*}{$0.008^{\mathrm{a}}$} \\
\hline Positive & $21(15.33)$ & $33(29.20)$ & \\
\hline \multicolumn{4}{|l|}{ Adjuvant chemotherapy } \\
\hline Yes & $37(27.0)$ & $64(56.64)$ & \multirow[t]{2}{*}{$<0.0001^{\mathrm{a}}$} \\
\hline No & $100(73.0)$ & $49(43.36)$ & \\
\hline \multicolumn{4}{|l|}{$\mathrm{CEA}(\mathrm{ng} / \mathrm{ml})$} \\
\hline$<5$ & $73(53.28)$ & $63(55.75)$ & \multirow[t]{2}{*}{0.69} \\
\hline$\geq 5$ & $64(46.72)$ & $50(44.25)$ & \\
\hline \multicolumn{4}{|l|}{ Recurrence } \\
\hline Negative & $114(83.21)$ & $85(75.22)$ & \multirow[t]{2}{*}{0.11} \\
\hline Positive & $23(16.79)$ & $28(24.78)$ & \\
\hline
\end{tabular}

B, Summary of recurrence in patients with stage II and stage III disease

\begin{tabular}{lcc}
\hline Patterns of recurrence & Stage II $n=23(\%)$ & Stage III $n=28(\%)$ \\
\hline Hematogenous recurrence & $16(69.6)$ & $19(67.8)$
\end{tabular}


Table I. Continued.

B, Summary of recurrence in patients with stage II and stage III disease

\begin{tabular}{lcc}
\hline Patterns of recurrence & Stage II $n=23(\%)$ & Stage III $n=28(\%)$ \\
\hline Lymphogenous recurrence & $3(13.0)$ & $2(7.2)$ \\
Disseminated recurrence & $4(17.4)$ & $7(25)$ \\
\hline
\end{tabular}

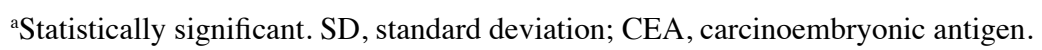

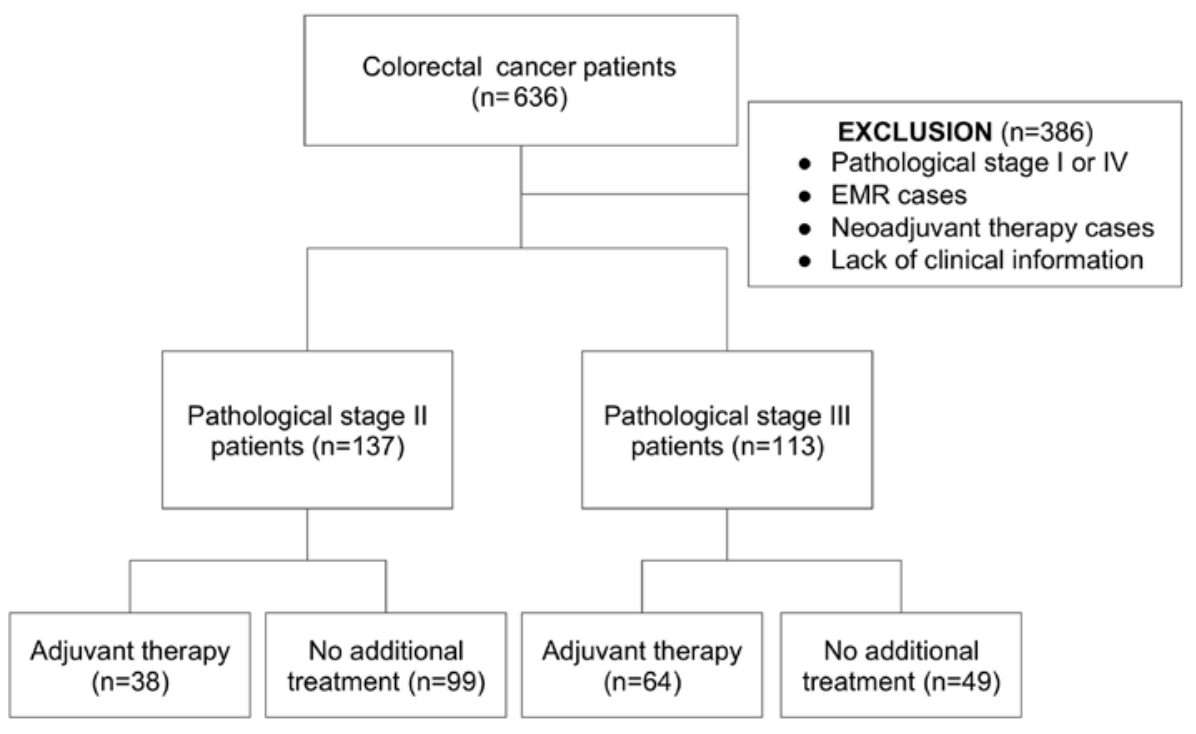

Figure 1. Flowchart of enrolled patients. EMR, endoscopic membrane resection.

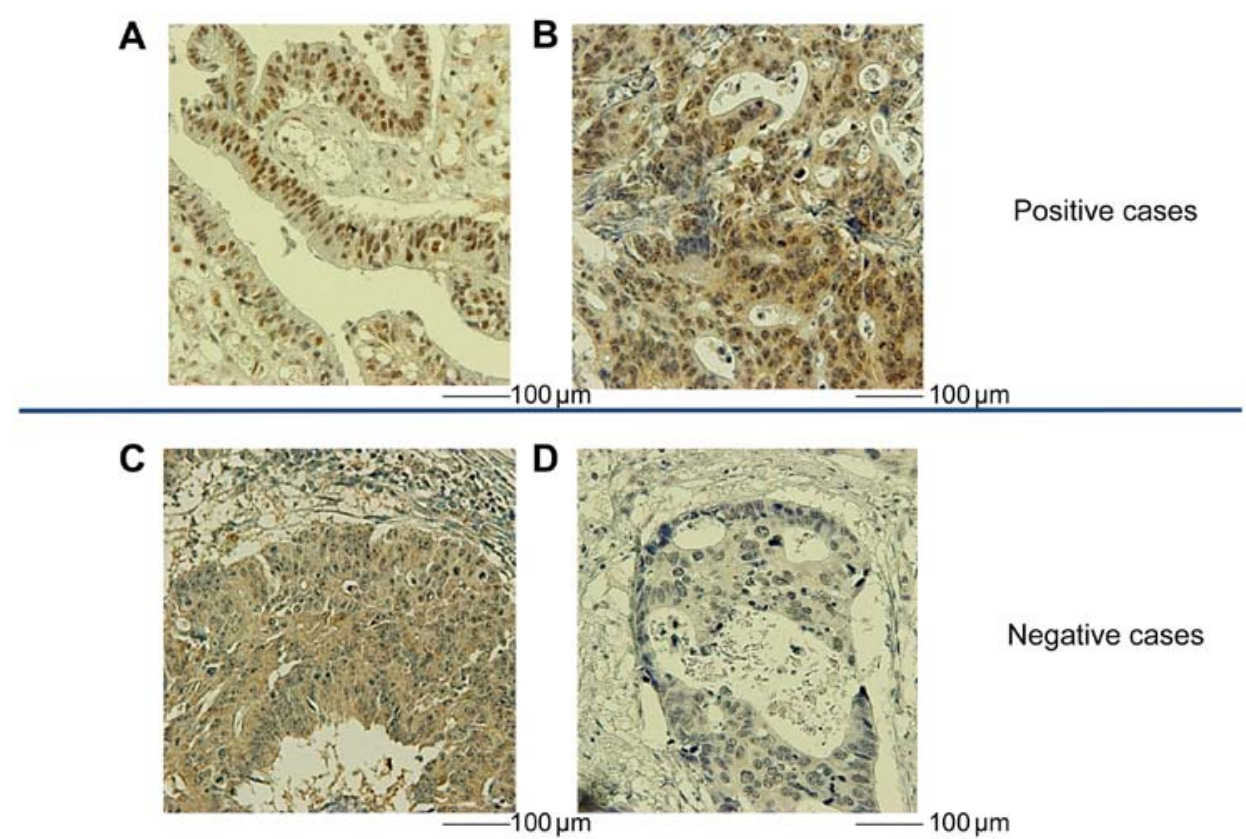

Figure 2. Schematic of representative immunohistochemical staining of Mina53. (A) Nuclear staining. (B) Nuclear and cytoplasmic staining. (C) Cytoplasmic staining. (D) Negative staining. All figures are shown at a magnification, x200.

Status of Mina53 in stage II and III CRC and clinicopathological variables. Patients were classified into Mina53-positive and -negative groups according to the immunohistochemical results. As shown in Table IIA, 148 out of 250 cases (59.6\%) 
Table II. Mina53 nuclear localization and clinicopathological variables and univariate/multivariate analyses of patients with stage II/III colorectal cancer.

A, Mina53 nuclear localization and clinicopathological variables

\begin{tabular}{|c|c|c|c|}
\hline Mina53 nuclear localization & Negative $(\%) \mathrm{n}=102$ & Positive $(\%) \mathrm{n}=148$ & P-value \\
\hline \multicolumn{4}{|l|}{ Sex } \\
\hline Male & $62(60.7)$ & $101(68.2)$ & \multirow[t]{2}{*}{0.224} \\
\hline Female & $40(39.3)$ & $47(31.8)$ & \\
\hline Age, average \pm SD & $65.79 \pm 1.13$ & $69.12 \pm 0.94$ & $0.0252^{\mathrm{a}}$ \\
\hline \multicolumn{4}{|l|}{$\mathrm{T}$ grade } \\
\hline $\mathrm{T} 1$ & $2(1.9)$ & $1(0.7)$ & \multirow[t]{4}{*}{0.24} \\
\hline $\mathrm{T} 2$ & $8(7.6)$ & $5(3.5)$ & \\
\hline $\mathrm{T} 3$ & $62(58.9)$ & $87(60.9)$ & \\
\hline $\mathrm{T} 4$ & $30(31.6)$ & $55(34.9)$ & \\
\hline \multicolumn{4}{|l|}{$\mathrm{N}$ grade } \\
\hline NO & $51(50.0)$ & $86(58.1)$ & \multirow[t]{4}{*}{0.139} \\
\hline N1 & $44(43.14)$ & $45(30.4)$ & \\
\hline $\mathrm{N} 2$ & $6(5.88)$ & $12(8.1)$ & \\
\hline N3 & $1(0.98)$ & $5(3.4)$ & \\
\hline \multicolumn{4}{|l|}{ Tumor stage } \\
\hline II & $51(50.0)$ & $86(58.1)$ & \multirow[t]{2}{*}{0.205} \\
\hline III & $51(50.0)$ & $62(41.2)$ & \\
\hline Tumor size $(\mathrm{mm})$, average $\pm \mathrm{SD}$ & $51.08 \pm 2.14$ & $49.56 \pm 1.78$ & 0.584 \\
\hline \multicolumn{4}{|l|}{ Location } \\
\hline Colon & $70(68.6)$ & $90(60.8)$ & \multirow[t]{2}{*}{0.204} \\
\hline Rectum & $32(31.4)$ & $58(39.2)$ & \\
\hline \multicolumn{4}{|l|}{ Histological type } \\
\hline Well-mod & $94(92.2)$ & $134(90.5)$ & \multirow[t]{2}{*}{0.656} \\
\hline Poorly & $8(7.8)$ & $14(9.5)$ & \\
\hline \multicolumn{4}{|l|}{ Lymphatic invasion } \\
\hline Negative & $33(32.4)$ & $62(41.9)$ & \multirow[t]{2}{*}{0.125} \\
\hline Positive & $69(67.6)$ & $86(58.1)$ & \\
\hline \multicolumn{4}{|l|}{ Vascular invasion } \\
\hline Negative & $25(24.5)$ & $23(15.5)$ & \multirow[t]{2}{*}{0.076} \\
\hline Positive & $77(75.5)$ & $125(54.5)$ & \\
\hline \multicolumn{4}{|l|}{ Tumor budding } \\
\hline Negative & $32(31.4)$ & $49(33.3)$ & \multirow[t]{2}{*}{0.745} \\
\hline Positive & $70(68.6)$ & $98(66.7)$ & \\
\hline \multicolumn{4}{|l|}{ Perineural invasion (PNI) } \\
\hline Negative & $83(81.4)$ & $113(76.4)$ & \multirow[t]{2}{*}{0.34} \\
\hline Positive & $19(18.6)$ & $35(23.6)$ & \\
\hline \multicolumn{4}{|l|}{ Adjuvant chemotherapy } \\
\hline Yes & $44(43.1)$ & $58(39.2)$ & \multirow[t]{2}{*}{0.532} \\
\hline No & $58(56.9)$ & $90(60.8)$ & \\
\hline \multicolumn{4}{|l|}{ CEA (ng/ml) } \\
\hline$<5$ & $55(53.9)$ & $81(54.7)$ & \multirow[t]{2}{*}{0.899} \\
\hline$\geq 5$ & $47(46.1)$ & $67(45.3)$ & \\
\hline Recurrence & & & \\
\hline Negative & $90(85.3)$ & $109(73.6)$ & $0.003^{\mathrm{a}}$ \\
\hline Positive & $12(11.7)$ & $39(26.4)$ & \\
\hline
\end{tabular}


Table II. Continued.

B, Univariate and multivariate analyses for relapse-free survival in patients with stage II/III colorectal cancer

\begin{tabular}{|c|c|c|c|c|c|c|}
\hline & Odds ratio & $95 \% \mathrm{CI}$ & $\mathrm{P}$-value & Odds ratio & $95 \% \mathrm{CI}$ & P-value \\
\hline \multicolumn{7}{|l|}{ Factors } \\
\hline \multicolumn{7}{|l|}{ Age } \\
\hline$\geq 67 /<67$ & 0.77 & $0.44-1.34$ & 0.35 & - & - & - \\
\hline \multicolumn{7}{|l|}{ Sex } \\
\hline Male/female & 1.05 & $0.6-1.94$ & 0.84 & - & - & - \\
\hline \multicolumn{7}{|l|}{ Primary tumor } \\
\hline T3-4/T2-1 & 1.86 & $0.57-11.42$ & 0.33 & - & - & - \\
\hline \multicolumn{7}{|l|}{ Tumor size } \\
\hline$\geq 50 /<50$ & 0.91 & $0.52-1.59$ & 0.76 & - & - & - \\
\hline \multicolumn{7}{|l|}{ Location } \\
\hline Colon/rectum & 0.67 & $0.37-1.17$ & 0.16 & - & - & - \\
\hline \multicolumn{7}{|l|}{ Histological type } \\
\hline Poor/well-mod & 6.83 & $2.36-15.72$ & $0.0014^{\mathrm{a}}$ & 7.62 & $2.6-17.9$ & $0.0009^{\mathrm{a}}$ \\
\hline \multicolumn{7}{|l|}{ Lymphatic invasion } \\
\hline \multicolumn{7}{|l|}{ Vascular invasion } \\
\hline $\mathrm{v}+/ \mathrm{v}-$ & 0.98 & $0.51-2.07$ & 0.95 & - & - & - \\
\hline \multicolumn{7}{|l|}{ Tumor budding } \\
\hline $\mathrm{b}+/ \mathrm{b}-$ & 1.19 & $0.66-2.28$ & 0.56 & - & - & - \\
\hline \multicolumn{7}{|l|}{ PNI } \\
\hline PNI+/PNI- & 1.44 & $0.75-2.6$ & 0.25 & - & - & - \\
\hline \multicolumn{7}{|c|}{ Adjuvant chemotherapy } \\
\hline Yes/no & 1.97 & $1.14-3.48$ & $0.0152^{\mathrm{a}}$ & 2.01 & $1.16-3.55$ & $0.0128^{\mathrm{a}}$ \\
\hline \multicolumn{7}{|l|}{ CEA } \\
\hline$>5.0 / \leq 5.0$ & 1.95 & $1.12-3.48$ & $0.0175^{\mathrm{a}}$ & 2.2 & $1.25-3.97$ & $0.0058^{\mathrm{a}}$ \\
\hline \multicolumn{7}{|l|}{ Mina53 status } \\
\hline Positive/negative & 2.58 & $1.39-5.16$ & $0.002^{\mathrm{a}}$ & 2.92 & $1.56-5.87$ & $0.0005^{\mathrm{a}}$ \\
\hline
\end{tabular}

${ }^{a}$ Statistical significance. 95\% CI, 95\% confidence interval; PNI, perineural invasion; CEA, carcinoembryonic antigen.

were assigned into the positive group. Neither $\mathrm{T}$ factor nor $\mathrm{N}$ factor were significantly correlated with Mina53 positivity. The percentage of Mina53-positive cases was almost identical in patients with stage II and III disease. There were no significant differences in the majority of clinicopathological factors, other than patient age and tumor recurrence, between the Mina53-positive and -negative groups. Vascular invasion was relatively higher in the Mina53-negative group than in the Mina53-positive group; however, this difference was not significant. Patient age was significantly higher in the Mina53-positive group. Tumor recurrence was also significantly higher in the Mina53-positive group than in the Mina53-negative group. Metastatic lesions did not differ significantly between the two groups. However, the Mina53-positive group exhibited significantly poorer RFS than the Mina53-negative group (Fig. 3).

To evaluate the influence of Mina53 nuclear expression on RFS, univariate and multivariate analyses were performed.

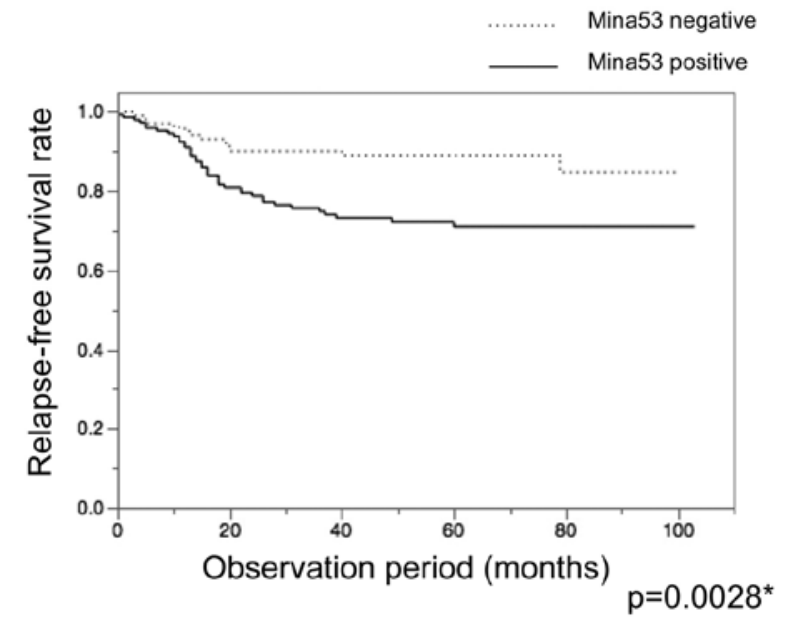

Figure 3. RFS rates for samples with and without Mina53 nuclear staining. Differences in RFS were assessed using the Kaplan-Meier method and compared using log-rank tests. RFS, relapse-free survival. 
A

Mina53 status

Histological type

CEA level

Adjuvant chemotherapy

B
FDR

2.754

2.754

2.111

1.892

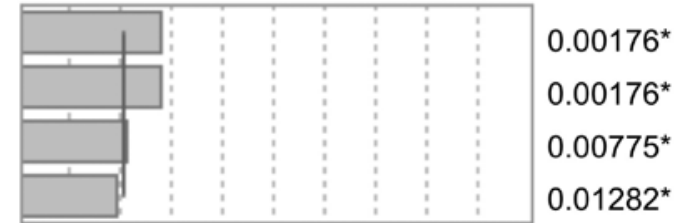

FDR

3.464

2.418 p-values

p-values

$0.00176^{\star}$

$0.00176^{\star}$

$0.00775^{*}$

$0.01282^{\star}$

$0.00034^{*}$

$0.00382^{\star}$

Figure 4. FDR comparison in multivariate analysis. (A) FDR comparison among significantly different clinicopathological variables by multivariate analysis for RFS in all stage II/III cases. (B) FDR comparison among significantly different clinicopathological variables in patients with stage III disease treated with adjuvant chemotherapy. FDR, false-discovery rate.

A
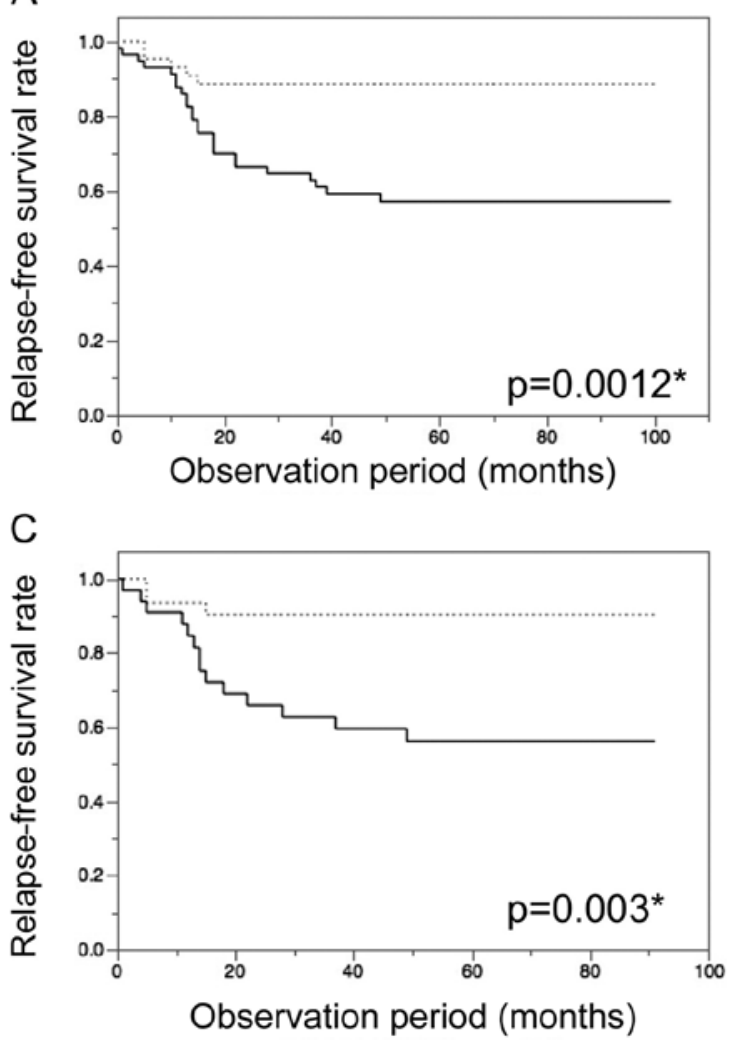

B

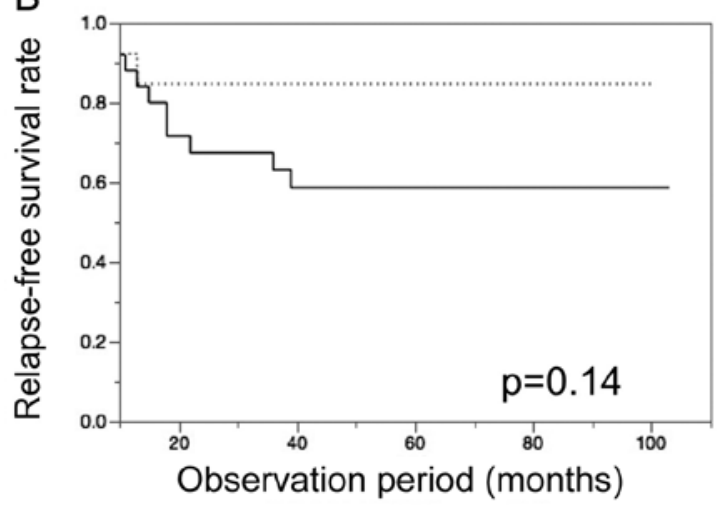

Mina53 negative

Mina53 positive

Figure 5. Comparison of RFS between samples with and without Mina53 nuclear staining. (A) RFS comparison in patients with stage II/III disease treated with adjuvant chemotherapy. (B) RFS comparison in patients with stage II disease treated with adjuvant chemotherapy. (C) RFS comparison in patients with stage III disease treated with adjuvant chemotherapy. RFS, relapse-free survival.

In the univariate analysis, histological type, adjuvant chemotherapy status, CEA status, and Mina53 status were prognostic factors for RFS in patients with stage II and stage III disease. In multivariate analysis, each of the variables selected in the univariate analysis became an independent prognostic factor for RFS (Table IIB). In false-discovery rate (FDR) analysis for RFS, Mina53 status and histological type were the most significantly contributing variables, followed by CEA level and adjuvant chemotherapy status (Fig. 4A).

Mina53 nuclear expression did not correlate with prognosis in patients who did not receive adjuvant chemotherapy.
Next, we performed an analysis of patients who had or had not undergone adjuvant chemotherapy (Fig. 1). There were no significant differences in RFS in the Mina53-positive and -negative groups in patients who did not receive adjuvant chemotherapy (data not shown). These results were also confirmed separately for patients with stage II and stage III disease (data not shown).

Mina53 nuclear expression was an indicator of poor prognosis in patients who had received adjuvant chemotherapy. Nuclear positivity of Mina53 was significantly associated with shorter RFS compared with that in the Mina53-negative 
Table III. Univariate and multivariate analyses for relapse-free survival in patients with stage III disease treated with adjuvant chemotherapy.

\begin{tabular}{|c|c|c|c|c|c|c|}
\hline & Odds ratio & $95 \% \mathrm{CI}$ & P-value & Odds ratio & $95 \% \mathrm{CI}$ & P-value \\
\hline \multicolumn{7}{|l|}{ Factors } \\
\hline \multicolumn{7}{|l|}{ Age } \\
\hline$\geq 67 /<67$ & 0.91 & $0.42-1.9$ & 0.81 & - & - & - \\
\hline \multicolumn{7}{|l|}{ Sex } \\
\hline Male/female & 0.79 & $0.37-1.73$ & 0.54 & - & - & - \\
\hline \multicolumn{7}{|l|}{ Primary tumor } \\
\hline T3-4/T2-1 & 3.59 & $0.76-64.12$ & 0.12 & - & - & - \\
\hline \multicolumn{7}{|l|}{ Tumor size } \\
\hline$\geq 50 /<50$ & 0.89 & $0.43-1.93$ & 0.78 & - & - & - \\
\hline \multicolumn{7}{|l|}{ Location } \\
\hline Colon/rectum & 1 & $0.46-2.09$ & 0.98 & - & - & - \\
\hline \multicolumn{7}{|l|}{ Histological type } \\
\hline Poor/well-mod & 2.56 & $1.17-6.15$ & $0.0167^{\mathrm{a}}$ & 3.11 & $1.42-7.51$ & $0.0038^{\mathrm{a}}$ \\
\hline \multicolumn{7}{|l|}{ Lymphatic invasion } \\
\hline ly+/ly- & 1.55 & $0.69-3.93$ & 0.29 & - & - & - \\
\hline \multicolumn{7}{|l|}{ Vascular invasion } \\
\hline $\mathrm{v}+/ \mathrm{v}-$ & 0.77 & $0.32-2.29$ & 0.61 & - & - & - \\
\hline \multicolumn{7}{|l|}{ Tumor budding } \\
\hline$b+/ b-$ & 1.8 & $0.78-4.88$ & 0.17 & - & - & - \\
\hline \multicolumn{7}{|l|}{ PNI } \\
\hline PNI+/PNI- & 0.93 & $0.37-2.08$ & 0.87 & - & - & - \\
\hline \multicolumn{7}{|l|}{ CEA } \\
\hline$>5.0 / \leq 5.0$ & 1.55 & $0.74-3.28$ & 0.23 & - & - & - \\
\hline \multicolumn{7}{|l|}{ Mina53 status } \\
\hline Positive/negative & 4.29 & $1.77-12.77$ & $0.0007^{\mathrm{a}}$ & 5.02 & $2.06-15$ & $0.0002^{\mathrm{a}}$ \\
\hline
\end{tabular}

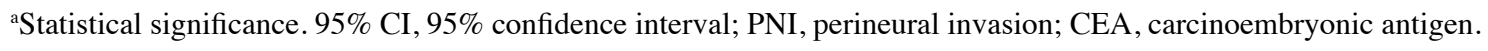

group (Fig. 5A). Furthermore, in subgroup analysis, there were no significant differences in RFS in patients with stage II disease who received adjuvant chemotherapy (Fig. 5B). However, patients treated with adjuvant chemotherapy in stage III exhibited a significantly shorter RFS (Fig. 5C).

Univariate and multivariate analyses were performed to determine which clinicopathological variables contributed to RFS (Table III). Histological type and Mina53 status were chosen as factors significantly contributing to RFS in both univariate and multivariate analyses. Furthermore, Mina53 was superior to histological status in the FDR analysis (Fig. 4B).

\section{Discussion}

In the present study, we focused on Mina53 nuclear expression in primary lesions in patients with stage II/III CRC treated with radical resection of the tumor. Of the 250 patients, 113 (45.2\%) had stage III disease, and of these 113, 49 patients (43.33\%) did not receive adjuvant chemotherapy. Currently, almost all patients with stage III disease receive adjuvant chemotherapy. However, the patients in this study were treated from 2005 to 2008, during which time the choice of therapy was at the discretion of the doctor, without an obvious consensus. Thus, many patients with stage III disease did not receive adjuvant chemotherapy.

There were no significant differences in RFS between Mina53-positive and -negative groups in patients with stage II disease; however, a difference was observed in patients with stage III disease. In Japan, the surgical procedure performed in patients with stage II/III disease allows for a sufficient surgical margin and lymphadenectomy around the main tumor feeder in the upstreaming artery (10). In patients with stage II disease, the lymphadenectomy procedure is thought to be sufficient for complete cancer resection. In contrast, in patients with stage III disease, there is a chance that some cancer cells are not fully resected. The residual cancer cells could cause recurrence and metastasis, thereby affecting RFS.

As reported previously, Mina53 is a direct target of the c-Myc proto-oncogene, which regulates cell proliferation, cell growth, differentiation, and apoptosis. c-Myc is a well-studied oncogene that is overexpressed in many cancers $(11,12)$. Tuneoka et al demonstrated that Mina53 expression is 
controlled by c-Myc (8). Thus, localization of Mina53 expression in the nucleus may reflect the activation of c-Myc. In this study, there were no significant differences in RFS between Mina53-negative and -positive groups in patients who did not undergo adjuvant chemotherapy. However, significantly poorer RFS was observed in the Mina53-positive group in patients who received adjuvant chemotherapy compared with those in patients who did not receive adjuvant chemotherapy. The correlations between Mina53 nuclear expression and clinicopathological variables were also analyzed, and recurrence was revealed to be significantly correlated with Mina53 positivity. Thus, these findings indicated that nuclear expression of Mina53 was associated with the acquisition of chemotherapy resistance and tumorigenic ability often observed in cancer stem cells. Mina53 is induced by Myc (8), which functions as a transcriptioN factor and reprogramming regulator in embryonic stem cells and cancer cells (13). Thus, Myc is also involved in the regulation of cancer stem cells. Consistent with our findings, several studies have demonstrated that cancer stem cells are related to chemotherapy resistance in many types of cancer (14-17).

In the present study, Mina53 nuclear expression was significantly associated with recurrence and was a biomarker of RFS in patients with stage II/III CRC treated with adjuvant chemotherapy. Several other biomarkers have been revealed to indicate prognosis after adjuvant chemotherapy. For example, Lin et al reported that pre-operative CEA levels, emergent operation for obstruction/perforation, lymphovascular invasion, and tumor depth were poor predictors of RFS in patients with stage II disease (18). Additionally, the presence of $K R A S$ and $B R A F$ mutations affects recurrence or metastasis after surgical treatment in patients with CRC (19). Mutations in epidermal growth factor receptor (EGFR) and p53 (20) or microsatellite instability (MSI) (21) have also been reported to be biomarkers of CRC. However, some markers have not been fully evaluated due to the long time required for analysis, as well as the cost and complexity of the assays. Notably, Mina53 nuclear expression could be detected using a simple IHC procedure. With this assay, it was relatively easy to determine whether Mina53 was expressed in the nucleus. Moreover, the assay is inexpensive when compared with other potential methods.

Targeting of c-Myc in clinical trials is quite difficult because c-Myc is involved in not only cancer cell proliferation but also normal cell development (22). Furthermore, c-Myc is involved in a number of molecular pathways associated with cell growth, cell proliferation, and gene regulation. Myc was identified more than 30 years ago (23-27). Teye et al reported that Mina53 is expressed in all pathological grades of colon cancer, but that it is not or is only weakly expressed in non-neoplastic colonic cells (9). They also demonstrated that suppression of Mina53 expression in vitro by Mina53-specific small interfering RNA suppressed the proliferation of CRC cell lines. This suppressive effect was thought to be a result of inhibition of Mina53, suggesting that Mina53 may be a direct target of c-Myc as well as an attractive target for controlling the c-Myc pathway in tumor cells without harming normal cells. Further studies are required to elucidate these mechanisms. Mina53 may not only be a crucial marker to predict the prognosis of colorectal cancer patients who received adjuvant chemotherapy, but may also be an important biological target to treat those patients who failed to respond to conventional chemotherapeutic treatment.

Mina53 nuclear expression in CRC cells was found to be associated with tumor recurrence and could be used as an effective marker for predicting the prognosis of patients with $\mathrm{CRC}$ who received adjuvant chemotherapy. By investigating Mina53 nuclear expression, patients who may experience tumor recurrence or metastasis quickly after adjuvant chemotherapy can be selected. Patients who received adjuvant chemotherapy should be carefully screened and followed after treatment if their primary tumor exhibited nuclear Mina53 expression.

\section{Acknowledgements}

The authors thank Nagako Shigenaga, Hiroko Takayama and Michiko Nagamatsu for their technical support.

\section{Funding}

No funding was received.

\section{Availability of data and materials}

The datasets used during the present study are available from the corresponding author upon reasonable request.

\section{Authors' contributions}

SF and TK conceived and designed the study. SF and TK performed the experiments. SF, TK and TS wrote the paper. SF, TK, TS, TM, TY, NY, TO, KT, KY, SN, MK and YA reviewed and edited the manuscript. All authors read and approved the manuscript and agree to be accountable for all aspects of the research in ensuring that the accuracy or integrity of any part of the work are appropriately investigated and resolved.

\section{Ethics approval and consent to participate}

All of the protocols used in this study were in compliance with the guidelines of the Ethics Committee of Kurume University School of Medicine. The protocol of the study was approved by the hospital Ethics Review Board (no. 203), and informed consent was obtained from all of the enrolled patients pre-operatively.

\section{Consent for publication}

Not applicable.

\section{Competing interests}

The authors declare that they have no competing interests.

\section{References}

1. Siegel R, Ma J, Zou Z and Jemal A: Cancer statistics, 2014. CA Cancer J Clin 64: 9-29, 2014

2. Kotake K, Honjo S, Sugihara K, Kato T, Kodaira S, Takahashi T, Yasutomi M, Muto T and Koyama Y: Changes in colorectal cancer during a 20-year period: An extended report from the multi-institutional registry of large bowel cancer, Japan. Dis Colon Rectum 46 (10 Suppl): S32-S43, 2003. 
3. Tamakoshi A,Nakamura K,Ukawa S, Okada E,Hirata M, Nagai A, Matsuda K, Kamatani Y, Muto K, Kiyohara Y, et al: Characteristics and prognosis of Japanese colorectal cancer patients: The BioBank Japan Project. J Epidemiol 27: S36-S42, 2017.

4. Shirota Y, Stoehlmacher J, Brabender J, Xiong YP, Uetake H, Danenberg KD, Groshen S, Tsao-Wei DD, Danenberg PV and Lenz HJ: ERCCl and thymidylate synthase mRNA levels predict survival for colorectal cancer patients receiving combination oxaliplatin and fluorouracil chemotherapy. J Clin Oncol 19: 4298-4304, 2001.

5. Crozier JEM, McKee RF, McArdle CS, Angerson WJ, Anderson JH, Horgan PG and McMillan DC: The presence of a systemic inflammatory response predicts poorer survival in patients receiving adjuvant 5-FU chemotherapy following potentially curative resection for colorectal cancer. Br J Cancer 94 1833-1836, 2006

6. Ogata Y, Matono K, Mizobe T, Ishibashi N, Mori S, Akagi Y, Ikeda S, Ozasa H, Murakami H and Shirouzu K: The expression of vascular endothelial growth factor determines the efficacy of post-operative adjuvant chemotherapy using oral fluoropyrimidines in stage II or III colorectal cancer. Oncol Rep 15: 1111-1116, 2006.

7. Ogawa M, Watanabe M, Mitsuyama Y, Anan T, Ohkuma M, Kobayashi T, Eto K and Yanaga K: Thymidine phosphorylase mRNA expression may be a predictor of response to postoperative adjuvant chemotherapy with $\mathrm{S}-1$ in patients with stage III colorectal cancer. Oncol Lett 8: 2463-2468, 2014.

8. Tsuneoka M, Koda Y, Soejima M, Teye K and Kimura H: A nove myc target gene, mina53, that is involved in cell proliferation. J Biol Chem 277: 35450-35459, 2002.

9. Teye K, Tsuneoka M, Arima N, Koda Y, Nakamura Y, Ueta Y, Shirouzu K and Kimura H: Increased expression of a Myc target gene Mina53 in human colon cancer. Am J Pathol 164: 205-216, 2004.

10. West NP, Kobayashi H, Takahashi K, Perrakis A, Weber K, Hohenberger W, Sugihara K and Quirke P: Understanding optimal colonic cancer surgery: Comparison of Japanese D3 resection and European complete mesocolic excision with central vascular ligation. J Clin Oncol 30: 1763-1769, 2012.

11. Stewart J, Evan G, Watson J and Sikora K: Detection of the c-myc oncogene product in colonic polyps and carcinomas. Br J Cancer 53: 1-6, 1986.

12. Sikora K, Chan S, Evan G, Gabra H, Markham N, Stewart J and Watson J: c-myc oncogene expression in colorectal cancer. Cancer 59: 1289-1295, 1987.

13. Kim J, Woo AJ, Chu J, Snow JW, Fujiwara Y, Kim CG, Cantor AB and Orkin SH: A Myc network accounts for similarities between embryonic stem and cancer cell transcription programs. Cell 143 313-324, 2010

14. Zhang Q, Shi S, Yen Y, Brown J, Ta JQ and Le AD: A subpopulation of $\mathrm{CD}_{133^{+}}$cancer stem-like cells characterized in human oral squamous cell carcinoma confer resistance to chemotherapy. Cancer Lett 289: 151-160, 2010.
15. Salcido CD, Larochelle A, Taylor BJ, Dunbar CE and Varticovski L: Molecular characterisation of side population cells with cancer stem cell-like characteristics in small-cell lung cancer. Br J Cancer 102: 1636-1644, 2010.

16. Bora-Singhal N, Perumal D, Nguyen J and Chellappan S: Glil-mediated regulation of Sox 2 facilitates self-renewal of stem-like cells and confers resistance to EGFR inhibitors in non-small cell lung cancer. Neoplasia 17: 538-551, 2015.

17. Zhang Y, Xu W, Guo H, Zhang Y, He Y, Lee SH, Song X, Li X, Guo Y, Zhao Y, et al: NOTCH1 signaling regulates self-renewal and platinum chemoresistance of cancer stem-like cells in human non-small cell lung cancer. Cancer Res 77: 3082-3091, 2017.

18. Lin HH, Chang YY, Lin JK, Jiang JK, Lin CC, Lan YT, Yang SH, Wang HS, Chen WS, Lin TC and Chang SC: The role of adjuvant chemotherapy in stage II colorectal cancer patients. Int J Colorectal Dis 29: 1237-1243, 2014.

19. Roth AD, Tejpar S, Delorenzi M, Yan P, Fiocca R, Klingbiel D, Dietrich D, Biesmans B, Bodoky G, Barone C, et al: Prognostic role of $K R A S$ and $B R A F$ in stage II and III resected colon cancer: Results of the translational study on the PETACC-3, EORTC 40993, SAKK 60-00 trial. J Clin Oncol 28: 466-474, 2010.

20. Resnick MB, Routhier J, Konkin T, Sabo E and Pricolo VE: Epidermal growth factor receptor, c-MET, beta-catenin, and p53 expression as prognostic indicators in stage II colon cancer: A tissue microarray study. Clin Cancer 10: 3069-3075, 2004.

21. Ribic CM, Sargent DJ, Moore MJ, Thibodeau SN, French AJ, Goldberg RM, Hamilton SR, Laurent-Puig P, Gryfe R, Shepherd LE, et al: Tumor microsatellite-instability status as a predictor of benefit from fluorouracil-based adjuvant chemotherapy for colon cancer. New Engl J Med 349: 247-257, 2003.

22. Davis AC, Wims M, Spotts GD, Hann SR and Bradley A: A null c-myc mutation causes lethality before 10.5 days of gestation in homozygotes and reduced fertility in heterozygous female mice. Genes Dev 7: 671-682, 1993.

23. Duesberg PH and Vogt PK: Avian acute leukemia viruses MC29 and MH2 share specific RNA sequences: Evidence for a second class of transforming genes. Proc Natl Acad Sci USA 76: 1633-1637, 1979

24. Sheiness D and Bishop JM: DNA and RNA from uninfected vertebrate cells contain nucleotide sequences related to the putative transforming gene of avian myelocytomatosis virus. J Virol 31: 514-521, 1979.

25. McKeown MR and Bradner JE: Therapeutic strategies to inhibit MYC. Cold Spring Harb Perspect Med 4: a014266, 2014.

26. Whitfield JR, Beaulieu M-E and Soucek L: Strategies to inhibit Myc and their clinical applicability. Front Cell Dev Biol 5: 10, 2017.

27. Chen BJ, Wu YL, Tanaka Y and Zhang W: Small molecules targeting c-Myc oncogene: Promising anti-cancer therapeutics. Int J Biol Sci 10: 1084-1096, 2014. 